\title{
Adubação de cobertura com enxofre na cultura da rúcula
}

\section{Michel Moreira Soares' ${ }^{1}$ Diógenes Martins Bardiviesso' ${ }^{1}$, Willams Ferreira Souza Barbosa1, Michelle Nunes Barcelos ${ }^{1}$}

${ }^{1}$ Universidade Estadual de Mato Grosso do Sul - UEMS, Unidade de Cassilândia, Cassilândia, Mato Grosso do Sul, Brasil. E-mail: michelmoreirasoares@gmail.com, bardiviesso@yahoo.com.br, willams93@hotmail.com, nunes-barcelos@bol.com.br

Recebido: 30/06/2016; Aceito: 01/02/2017

\section{RESUMO}

O enxofre apresenta grande importância para o desenvolvimento das culturas, sendo normalmente constatado o aumento da produtividade com o fornecimento deste nutriente em cobertura, entretanto, há poucos estudos que relatam o efeito da adubação com enxofre na cultura da rúcula (Eruca sativa). Portanto, o objetivo foi de avaliar o desenvolvimento da cultura da rúcula submetida à adubação com enxofre aplicado em cobertura. $O$ delineamento experimental utilizado foi o de blocos ao acaso, com cinco tratamentos $\left(0 ; 20 ; 40 ; 60 ; 80 \mathrm{mg}\right.$ de S planta $\left.{ }^{-1}\right) \mathrm{e}$ quatro repetições, cada parcela foi constituída por 5 vasos, com quatro plantas cada. Durante o desenvolvimento das plantas foi avaliada a intensidade de cor verde das folhas aos 16, 23 e 30 dias após a emergência. Aos 30 dias após a emergência (final do ciclo) foram avaliados o número de folhas, altura, massa seca da parte aérea, massa seca da raiz e massa seca total. A adubação com enxofre em cobertura aumenta a intensidade de cor verde das folhas de rúcula.

Palavras-chave: Eruca sativa, sulfato de amônio, nutrição das plantas.

\section{Topdressing arugula crop with sulfur}

\begin{abstract}
Sulfur has great importance for the development of crops and is usually found increased productivity with the supply of this nutrient in coverage; however, there are few studies reporting the effect of topdressing arugula with sulfur. Therefore, the objective was to evaluate the development of the arugula crop subjected to sulfur aplication in topdressing. The experimental design was randomized blocks, with five treatments $(0 ; 20 ; 40 ; 60 ; 80 \mathrm{mg} \mathrm{S}$ per plant) and four replications, each plot consisted of five pots, with four plants each. During the plant development was evaluated the green color intensity of the leaves at 16, 23 and 30 days after emergence. At 30 days after emergence (end of cycle) were evaluated the number of leaves, plant height, shoot dry matter, root dry mass and total dry mass. Topdressing arugula with sulfur increases the green color intensity of leaves.
\end{abstract}

Key words: Eruca sativa, ammonium sulfate, plant nutrition. 


\section{Introdução}

A rúcula se caracteriza por ser uma planta herbácea, de ciclo anual, que tem seu crescimento e desenvolvimento favorecido por temperaturas amenas, podendo atingir de 10 a $30 \mathrm{~cm}$ de altura na época da colheita, sendo recomendado fazer a colheita entre 3550 dias após o plantio, e que dependendo da variedade e das condições de cultivo pode se obter até 3 cortes antes do florescimento (FILGUEIRA, 2000).

$\mathrm{O}$ enxofre (S) é absorvido pelas plantas na forma de aniônica de sulfato $\left(\mathrm{SO}_{4}{ }^{2-}\right)$, encontrando-se uma grande parte na matéria orgânica, e uma pequena proporção na atmosfera, na forma de gás sulfúrico. Quando há deficiência deste macronutriente secundário, a síntese de proteína é inibida porque o $\mathrm{S}$ é participante de dois aminoácidos essenciais (cistina e a metionina), como consequência as plantas apresentam menor teor de clorofila e raízes menos desenvolvidas (RAIJ, 2011).

Não há duvidas quanto à eficiência deste nutriente, mas a grande dificuldade da utilização de $\mathrm{S}$ consiste na ausência dele nas formulações NPK. No entanto, podese encontrar no mercado de insumos diversos fertilizantes que contém certa quantidade de S como, superfosfato simples, sulfato de amônio e sulfato de potássio (RAIJ, 2011).

Segundo Stipp e Casarin (2010) e Hobuss et al. (2007) mesmo que o $\mathrm{S}$ possa ter parte suprida pela atmosfera e pela matéria orgânica não se pode deixar de empregar fontes artificiais desse nutriente, sendo necessária uma recomendação bastante criteriosa para se obter sucesso no uso deste elemento.

Devido à falta de dados e pesquisas realizadas com a cultura da rúcula, muitos resultados obtidos com a cultura da alface e outras culturas são utilizados no cultivo da rúcula. Segundo Resende et al. (2011), a adubação com enxofre aplicado em cobertura na cultura do alho é bastante rentável pois proporciona aumento na altura da planta, número de folhas, massa seca, e melhora a absorção de outros nutrientes devido ao aumento no tamanho do sistema radicular.

Resultados com adubação com enxofre não são obtidos apenas em hortaliças, a maioria das culturas tem apresentado resposta satisfatória. Crusciol et al. (2006) observaram na cultura de feijoeiro um aumento significativo na produção de massa seca da parte aérea, aumento no número de vagens e como consequência aumento na produtividade de grãos.

Estudos avaliando o efeito da aplicação de enxofre na cultura da rúcula são incipientes e escassos, portanto o objetivo foi de avaliar o desenvolvimento da cultura da rúcula submetida à adubação em cobertura com enxofre.

\section{Material e Métodos}

O experimento foi conduzido em casa de vegetação na Universidade Estadual de Mato Grosso do Sul, Unidade de Cassilândia-MS, no período de 17/02/2016 a 30/04/2016, as coordenadas geográficas do local do experimento são: altitude de $471 \mathrm{~m}, 19^{\circ} 5^{\prime} 32^{\prime}$ 'S de latitude e $51^{\circ} 48^{\prime} 47^{\prime \prime} \mathrm{O}$ de longitude, com clima tropical chuvoso no verão e seco no inverno (Aw).

O delineamento experimental utilizado foi de blocos ao acaso, com cinco tratamentos e quatro repetições, constituindo vinte parcelas. Cada parcela foi constituída por cinco vasos de $5 \mathrm{~L}$, contendo quatro plantas cada.

Os vasos foram preenchidos com solo classificado como Neossolo Quartzarênico Órtico baseado na classificação de Santos et al. (2013). As análises granulométrica e química apresentam os seguintes resultados: areia $=855 \mathrm{~g} \mathrm{~kg}^{-1}$, silte $=50 \mathrm{~g} \mathrm{~kg}^{-1}$, argila $=$ $95 \mathrm{~g} \mathrm{~kg}^{-1}, \mathrm{pH}\left(\mathrm{CaCl}_{2}\right)=4,2 ; \mathrm{M} . \mathrm{O}=12 \mathrm{mg} \mathrm{dm}^{-3} ; \mathrm{P}$ $($ resina $)=4 \mathrm{mg} \mathrm{dm}^{-3} ; \mathrm{K}=1,5 \mathrm{mmol}_{\mathrm{c}} \mathrm{dm}^{-3} ; \mathrm{Ca}=8 \mathrm{mmol}_{\mathrm{c}}$ $\mathrm{dm}^{-3} ; \mathrm{Mg}=8 \mathrm{mmol}_{\mathrm{c}} \mathrm{dm}^{-3} ; \mathrm{S}=5 \mathrm{mg} \mathrm{dm}^{-3}, \mathrm{H}+\mathrm{Al}=40$ $\mathrm{mmol}_{\mathrm{c}} \mathrm{dm}^{-3}, \mathrm{CTC}=58 \mathrm{mmol}_{\mathrm{c}} \mathrm{dm}^{-3}, \mathrm{~V}=31 \%, \mathrm{~B}=0,16$ $\mathrm{mg} \mathrm{dm}^{-3}, \mathrm{Cu}=1,0 \mathrm{mg} \mathrm{dm}^{-3}, \mathrm{Fe}=15 \mathrm{mg} \mathrm{dm}^{-3}, \mathrm{Mn}=5,1$ $\mathrm{mg} \mathrm{dm}{ }^{-3}, \mathrm{Zn}=0,2 \mathrm{mg} \mathrm{dm}^{-3}$.

O solo foi corrigido com 6,5 $\mathrm{g}$ de calcário (PRNT $87 \%$ ) por vaso, e fertilizado com $2,45 \mathrm{~g}$ de superfosfato triplo ( $41 \%$ de $\left.\mathrm{P}_{2} \mathrm{O}_{5}\right), 0,6 \mathrm{~g}$ de cloreto de potássio $(60 \%$ de $\mathrm{K}_{2} \mathrm{O}$ ), 0,135 g de FTE BR-12 (9\% de $\mathrm{Zn}, 1,8 \%$ de B, $0,8 \%$ de $\mathrm{Cu}, 2 \%$ de $\mathrm{Mn}, 3,5 \%$ de $\mathrm{Fe}$ e $0,1 \%$ de $\mathrm{Mo}$ ) e 0,22 g de ureia ( $45 \%$ de N) por vaso. Após a correção os vasos foram incubados por 30 dias.

O plantio foi realizado dia 17 de março de 2016 por meio de semeadura direta, utilizando-se sementes de cultivar folha larga com potencial de germinação de $85 \%$, sendo semeado em média 10 sementes por vaso. Três dias após a semeadura ocorreu a germinação e 10 dias após a ocorrência da mesma efetuou-se o desbaste.

A adubação de cobertura foi realizada com $0,20,40$, 60 e $80 \mathrm{mg}$ planta $^{-1}$ de $\mathrm{S}$, fornecido na forma de sulfato de amônio ( $20 \%$ de $\mathrm{N}$ e $22 \%$ de $\mathrm{S}$ ) aos 7 , 14, e 21 dias após a emergência das plantas. Concomitantemente com aplicação de sulfato de amônio foi realizada a adubação com ureia (45\% de $\mathrm{N}$ ) visando manter a dose de $80 \mathrm{mg}$ de $\mathrm{N}$ por planta em todos os tratamentos, sendo dissolvidos para facilitar a aplicação.

Os vasos foram molhados por meio de rega manual, no período da manhã e à tarde, visando manter a umidade do solo próximo da capacidade de campo.

Medidas de intensidade de cor verde das folhas (CCI) foram realizadas com o auxílio do equipamento CCM-200 desenvolvido pela empresa Opti-Sciences ${ }^{\circledR}$, que realiza esta determinação no local de coleta de forma instantânea, sendo os valores dados em CCI (unidade de medida determinada pela empresa Opti- 
Sciences $^{\square}$ ). As leituras foram realizadas aos 16, 23 e 30 dias após a emergência, sendo utilizadas 10 medidas por parcela. As leituras foram realizadas no período entre $8 \mathrm{~h}$ e $10 \mathrm{~h}$.

Aos trinta dias após a emergência foram avaliados a altura de planta e o número de folhas. Para a determinação da altura de plantas foram utilizadas duas plantas por vaso (10 plantas por parcela), sendo medida com régua graduada de $30 \mathrm{~cm}$ colocada rente ao solo até a altura da folha maior. Para o número de folhas foram utilizadas todas as plantas da parcela.

Após as avaliações da altura de plantas e do número de folhas por planta, a parte aérea foi separada da raiz com auxílio de uma tesoura de poda, para realização da secagem. A massa seca da raiz e da parte aérea foram obtidas após secagem em estufa de circulação forçada de ar a $65{ }^{\circ} \mathrm{C}$ por 72 horas, sendo depois procedida a pesagem em balança analítica eletrônica, com precisão de $0,001 \mathrm{~g}$. Com a soma das duas medições (massa seca da raiz e da parte aérea) foi obtida a massa seca total por planta.

Os dados das características avaliadas foram submetidos ao teste $\mathrm{F}$, posteriormente as variáveis com efeito significativo foram ajustadas à um modelo de regressão, com significância mínima de 5\% pelo teste $\mathrm{t}$ para os parâmetros da equação. Para as análises estatísticas foi utilizado o programa SISVAR (FERREIRA, 2003).

\section{Resultados e Discussão}

Houve diferença significativa apenas para intensidade de cor verde das folhas e número de folhas. Para os dados da intensidade de cor verde das folhas aos 16, 23 e 30 dias após a emergência, constatou-se ajuste linear, sendo a dose de $80 \mathrm{mg}$ por planta de $\mathrm{S}$ a que proporcionou a maior intensidade de cor verde da folha (Figura 1).

Com o uso de doses crescentes de enxofre foi possível observar por meio de regressão linear um maior número de folhas quando foi utilizada a maior dose de $80 \mathrm{mg}$ planta $^{-1}$ (Figura 2). Resultados semelhantes foram obtidos por Resende et al. (2011), na cultura do alho, onde obteve incremento no número de folhas devido ao uso complementar de enxofre.

$\mathrm{O}$ aumento da intensidade de cor verde das folhas com a elevação das doses de $\mathrm{S}$ deve-se influência do enxofre na síntese de clorofila e na fotossíntese, sendo um importante componente das feredoxinas e tieredoxinas (MALAVOLTA, 2006). Além disso, o enxofre tem uma relação muito forte com o nitrogenio, mesmo não sendo participante da clorofila exerce um papel fundamental na ativação da enzima redutase do nitrato melhorando o metabolismo do nitrogênio e influenciando de maneira indireta na formação clorofila (LOPES, 1998).
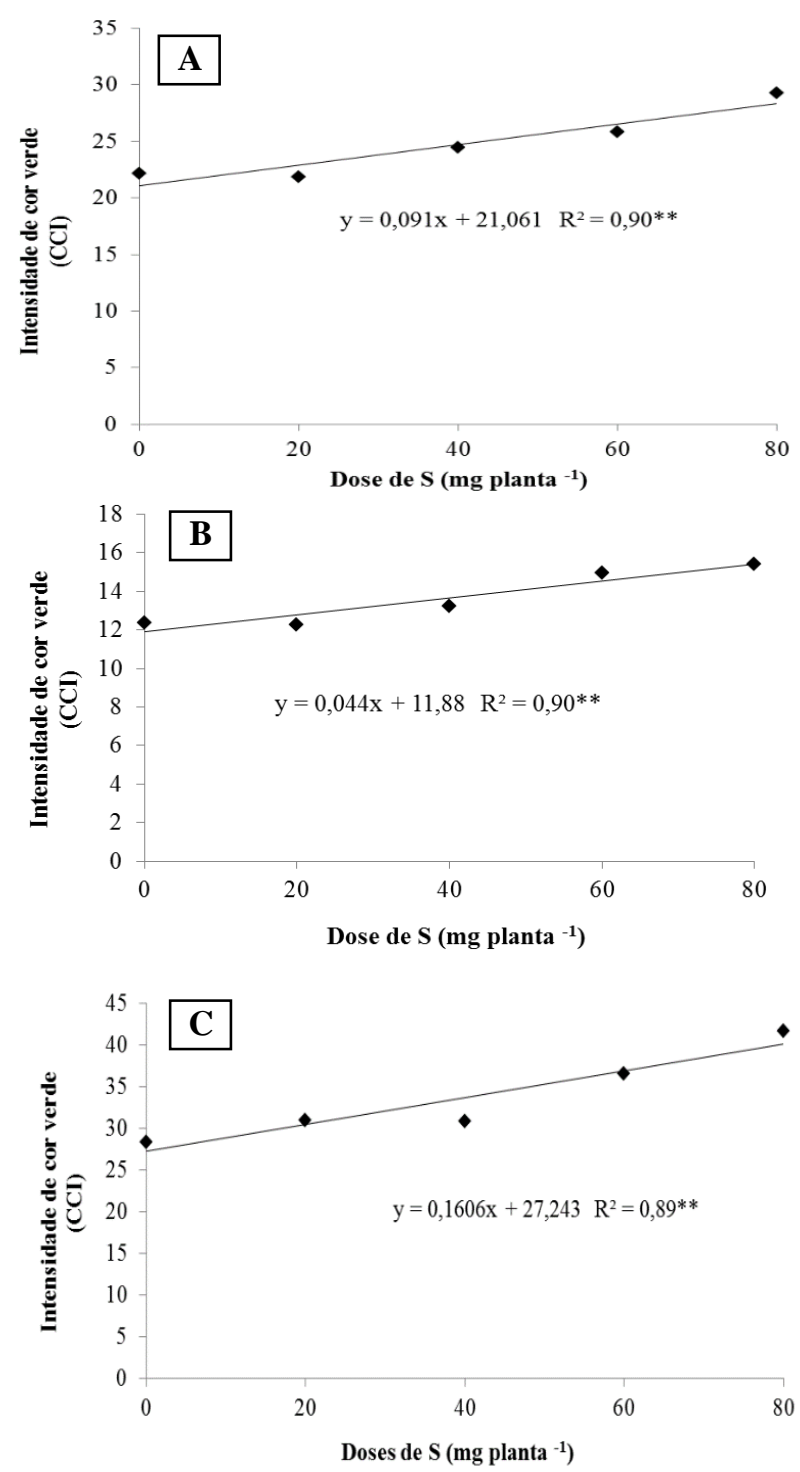

Figura 1. Intensidade de cor verde (CCI) das folhas de rúcula em função das doses de enxofre aplicadas em cobertura, avaliada aos 16 (A), 23 (B) e 30 (C) dias após a emergência das plantas. Cassilândia, MS. 2016.

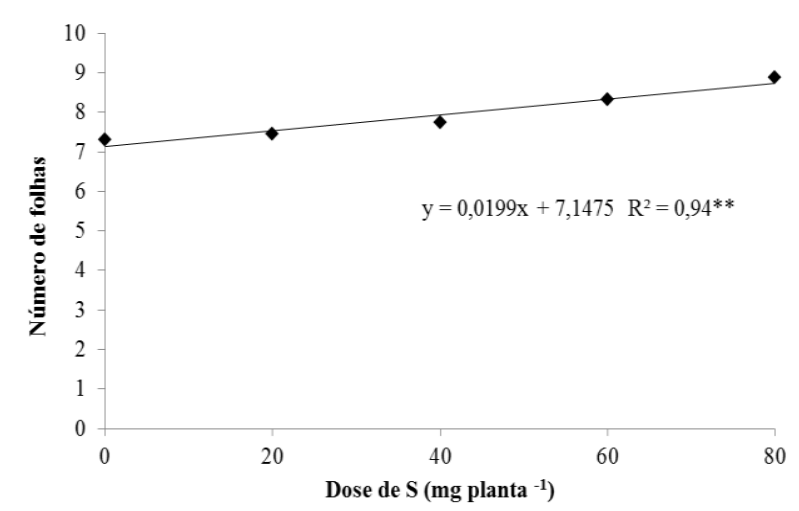

Figura 2. Número de folhas por planta de rúcula em função de doses de enxofre aplicadas em cobertura, avaliada ao final do ciclo da cultura. Cassilândia, MS. 2016. 
$\mathrm{O}$ incremento na intensidade de cor verde das folhas com o fornecimento de $\mathrm{S}$ também foi constatado por Lavres Júnior et al. (2008) em capim-Marandu (Urochloa brizantha) e por Almeida et al. (2011) na cultura da alface. De acordo com Almeida et al. (2011), a falta de enxofre na alface gera sintomas de clorose nas folhas mais novas, o que reduz a intensidade de cor verde das folhas.

A maior intensidade de cor verde das folhas proporciona uma melhor qualidade do produto, pois o mesmo fica mais atrativo, já que os consumidores têm preferência por folhas mais verdes e vigorosas. Além disso, Henz e Mattos (2008) relatam que para se consumir um alimento de qualidade, os nutricionistas e profissionais da área de gastronomia recomendam a escolha de folhas mais verdes e brilhantes.

Não houve diferença significativa para a altura de plantas, massa seca da parte aérea, massa seca da raiz e massa seca total. A falta de resposta dessas variáveis a adubação com enxofre deve-se provavelmente a concentração de $\mathrm{S}$ no solo $\left(5 \mathrm{mg} \mathrm{dm}^{-3}\right)$ que é considera média (entre 5 e $10 \mathrm{mg} \mathrm{dm}^{-3}$ ) segundo Souza e Lobato (2004). Tal fato sugere que a rúcula é uma planta pouco responsiva a adubação com enxofre.

\section{Conclusões}

Recomenda-se a aplicação de enxofre em cobertura na cultura da rúcula (Eruca sativa) para a produção de folhas com maior intensidade de cor verde, devendo optar se pela fonte de enxofre mais barata disponível no mercado.

\section{Referências Bibliográficas}

ALMEIDA, T. B. F.; PRADO, R. M.; CORREIRA, M. A. R.; PUGA, A. P.; BARBOSA, J. C. Avaliação nutricional da alface cultivada em soluções nutritivas suprimidas de macronutrientes. Revista Biotemas, Jaboticabal-SP, v. 24, n. 2, p.27-36, 2011.

CRUSCIOL, C. A. C.; SORATTO, R. P.; SILVA, L. M.; LEMOS, L. B. Aplicação de enxofre em cobertura no feijoeiro em sistema de plantio direto. Bragantia, Campinas-SP, v. 65, n. 3, p.459-465, 2006.
FILGUEIRA, F. A. R. Novo manual de olericultura: agrotecnologia moderna na produção e comercialização de hortaliças. Viçosa-MG: UFV, 2000. 402p.

FERREIRA, D. F. SISVAR versão 4.3 (Buid 45). LavrasMG: DEX/UFLA, 2003.

HENZ, G. P.; MATTOS, L. M. Manuseio pós-colheita de rúcula. Brasilia-DF: Embrapa Hortaliças, 2008. 7p. (Comunicado Técnico 64).

HOBUSS, C.; VENZKE, D.; GOUVEIA, D.; GOBEL, L.; KROLOW M.; DEVANTIER, P.; ALVES, R.; JACONDINO, V. Ciclo do Enxofre. Pelotas-RS: Universidade Federal de Pelotas, 2007. 10p.

LAVRES JÚNIOR, J.; MONTEIO, F.A.; SCHIAVUZZO, P.F. Concentração de enxofre, valor SPAD e produção do capim-Marandu em resposta ao enxofre. Revista Brasileira de Ciências Agrárias, Recife-PE, v.3, n.3, p.225-231, 2008.

LOPES, A.S. Manual internacional de fertilidade do solo. Piracicaba-SP: Associação Brasileira para pesquisa da potassa e do fosfato. 1998. 177p.

MALAVOLTA, E. Manual de nutrição mineral de plantas. São Paulo-SP: Editora Agronômica Ceres, 2006. 638p.

RAIJ, B. V. Fertilidade do solo e manejo de nutrientes. Piracicaba-SP: International Plant Nutrition Institute, 2011. 420p.

RESENDE, T.V.J.; MORALES, R.G.F.; RESENDE, F.V.; CARMINARRIL, R.; BERTUZZOL, L. L. C.; FIGUEIREDO, A.S.T. Aplicação complementar de enxofre em diferentes doses na cultura do alho. Horticultura Brasileira, BrasíliaDF, v.29, n. 2, p.217-221, 2011.

SANTOS, H. G.; JACOMINE, P. K. T.; ANJOS, L. H. C.; OLIVEIRA, V. A.; LUMBRERAS, J. F.; COELHO, M. R.; ALMEIDA, J. A.; CUNHA, T. J. F.; OLIVEIRA, J. B. Sistema Brasileiro de Classificação de Solos. Brasília-DF: EMBRAPA, 2013. 353p.

SOUZA, D. M. G; LOBATO, E. Cerrado: correção do solo e adubação. $2^{\mathrm{a}}$ ed. Brasília-DF: Embrapa Cerrado, 2004. 416p.

STIPP, S.R.; CASARIN, V. A importância do enxofre na agricultura brasileira. Piracicaba-SP: IPNI, 2010. 20p. (Informações Agronômicas n. 129). 